\title{
Surface Modification of Carbon Fibres for Interface Improvement in Textile Composites
}

\author{
Jiawen Qiu ${ }^{1} \cdot$ Jiashen $\mathrm{Li}^{1} \cdot$ Zishun Yuan ${ }^{1}$.

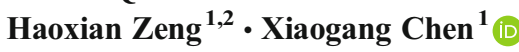

Received: 2 May 2018 / Accepted: 3 July 2018 / Published online: 15 August 2018

(C) The Author(s) 2018

\begin{abstract}
The performance of carbon fibre-reinforced composites is dependent to a great extent on the properties of fibre-matrix interface. In this research, based on the reviewed surface modification technique and inspired by the in situ growth of three-dimensional graphene coatings on nanomaterials, a new method of in situ growth of a graphene-related structure on the surface of carbon fibres is to be applied, for which it is intended to use a mixed solution of Ferrous Sulfate Heptahydrate $\left(\mathrm{FeSO}_{4} \cdot 7 \mathrm{H}_{2} \mathrm{O}\right)$ and D-Glucose monohydrate $\left(\mathrm{C}_{6} \mathrm{H}_{12} \mathrm{O}_{6} \cdot \mathrm{H}_{2} \mathrm{O}\right)$ to treat the carbon fibres under specific conditions to in-situ growth of a graphene-related coatings on the surface of carbon fibres. Firstly, the method was carried out by heating the mixed solution under specific temperature on the silicon wafer substrate and followed with characterisation experiments such as Raman and Scanning Electron Microscopy (SEM). Then, the mixed solution was applied on the carbon fibres and treated under the same condition. The characterisation results indicated successfully growth of the porous carbon coatings on the surface of the carbon fibres, which contained with graphene-related structures, while other characterization experiment like Transition Electron Microscopy (TEM) and X-ray Photoelectron Spectroscopy (XPS) will need to be used to further characterise the porous carbon structure. The interfacial shear strength between the fibre and the porous carbon coating also need to be characterised by using the micro-bond test.
\end{abstract}

Keywords Carbon fibre modification · Graphene $\cdot$ Composites $\cdot$ Characterisation $\cdot$ Interface

\section{Introduction}

Carbon fibres reinforced composites have the superior stiffness to weight and strength-toweight ratios, which have been used in a large number of high-performance structural

Xiaogang Chen

xiaogang_chen@hotmail.com

1 School of Materials, University of Manchester, Manchester M13 9PL, UK

2 School of Science, Zhongyuan University of Technology, Zhengzhou, China 
applications such as the automotive, aerospace, military defence and new energy [1]. Properties of fibre reinforced composites are affected by the interface between fibres and matrix [2]. Fibre-matrix interfacial adhesion is extremely important since carbon fibres have chemical inertness and poor wettability with most of the polymeric matrices [3].

The interface between the fibre and the matrix of composites materials is a very important aspect of the mechanism, which can affect the load transfer characteristics and mechanical behaviour under external loading. The wetting, dispersion and interface adhesion between fibre and matrix are key factors in designing fibre reinforced composites [4-6]. Studies in the effect of chemical vapor deposition (CVD) grafting on the mechanical properties of carbon/ epoxy composites started decades ago. The synthesis of 3D graphene layers on non-metal substrates by using the CVD method also has been accomplished [7-9]. In continuous fibrereinforced composites, the load is transferred from the matrix to the fibre through shear. With poor interfacial strength, shear stress is not able to be transferred to the fibre effectively, thus creating a weaker and less efficient composite [3]. The commercial carbon fibres are coated with a thin layer of epoxy resin, which is used to improve the handling and to decrease damage during processing and handling [3]. Removal of commercial sizing can also improve the surface chemical reactivity, which is beneficial to the enhancement of the fibre/resin interface, and make the catalyst precursors and carbon sources locate on the carbon fibre easily [10]. Zhang et al. have used acetone to treat the carbon fibre to remove the commercial size from the surface of the carbon fibre [2]. In the study by Li et al. they used $65 \mathrm{wt} \% \mathrm{HNO}_{3}$ to remove the size and also to introduce some carboxyl groups on to the carbon fibre [11].

Inspired by the in situ growth of three-dimensional graphene coatings on nanomaterials [7, 12-15], this paper proposes a method of in-situ growth of graphene-related structure on the surface of carbon fibres, aiming for the improvement of the fibre/resin interface. A mixed solution of a catalyst, ferrous sulfate heptahydrate $\left(\mathrm{FeSO}_{4} \cdot 7 \mathrm{H}_{2} \mathrm{O}\right)$, and a carbon source, Dglucose monohydrate $\left(\mathrm{C}_{6} \mathrm{H}_{12} \mathrm{O}_{6} \cdot \mathrm{H}_{2} \mathrm{O}\right)$, is used to treat the carbon fibres, before Heating the treated carbon fibres in a tube-furnace under specific conditions to in-situ grow a graphenerelated coating on the surface of carbon fibres. The in-situ growth of graphene-related coating is believed to be able to improve the interface adhesion between the carbon fibre and the resin.

\section{Experimental Section}

\subsection{Materials}

The carbon fibres used in this research were $12 \mathrm{~K} \mathrm{~A}-42$ DowAksa (Turkey), and ferrous sulfate heptahydrate $\left(\mathrm{FeSO}_{4} \cdot 7 \mathrm{H}_{2} \mathrm{O}\right)$ and D-glucose monohydrate $\left(\mathrm{C}_{6} \mathrm{H}_{12} \mathrm{O}_{6} \cdot \mathrm{H}_{2} \mathrm{O}\right)$ were purchased from Fisher Scientific and Sigma-Aldrich ${ }^{\circledR}(\mathrm{UK})$ respectively. The nitric acid $\left(\mathrm{HNO}_{3}\right)$ and acetone $\left(\mathrm{CH}_{3} \mathrm{COCH}_{3}\right)$ were also purchased from Sigma-Aldrich ${ }^{\circledR}(\mathrm{UK})$.

\subsection{Methodology}

Qian et al. [16] used the chemical vapour deposition (CVD) method to grow carbon nanotubes on carbon fibres. Iron was selected as the catalyst and pre-deposited on carbon fibres directly for the formation of carbon nano-tubes (CNT). Small holes were observed on some fracture surfaces of the CNT-grafted fibre composites and the formation of the pits was attributed to "the dissolution of iron into the carbon fibres" at the reaction temperature [13], leading to 
weakened carbon fibres. Also based on the CVD methods, Zhang et al. [7] constructed in-situ 2D graphene sheets on the bulk metal substrates by introducing a trace amount of transition metal salts and solid carbon sources with strictly controlled content and ratio.

In the design of this experiment, iron and an extra carbon source material are coated to carbon fibres, so that the extra carbon source can help to restrict the iron particles to a small size. The iron particles near the carbon fibre dissolve carbon atoms both from the carbon fibre and the extra carbon source at high temperature. When the temperature decreases, carbon atoms are released from the iron particles and they form graphene-related layers. Thus, these graphene-related layers are grown in-situ and have primary contact with the carbon fibres as shown in Fig. 1. C-C bonds are expected between the graphene-related structure and the carbon fibres, but not other chemically grafted GO with covalent bonds [11], which cannot survive high temperature during the following CVD process. It is envisaged that the interface strength between the carbon fibre and the grapheme created in this research are increased. In order to achieve the best condition of growing graphene-related coatings on the surface of carbon fibres, the preliminary experiments were carried out on a silicon wafer substrate firstly before applying on the carbon fibres.

\section{Growth of Graphene-Related Coatings}

The mixed solution, made by dissolving ferrous sulfate heptahydrate $\left(\mathrm{FeSO}_{4} \cdot 7 \mathrm{H}_{2} \mathrm{O}\right)$ as the catalyst precursor and glucose monohydrate $\left(\mathrm{C}_{6} \mathrm{H}_{12} \mathrm{O}_{6} \cdot \mathrm{H}_{2} \mathrm{O}\right)$ as the carbon source into deionized water at a weight ratio of 1:10:16, was used to coat the carbon fibre [7, 13], aiming at the in-situ growth of porous carbon structures on the surface of carbon fibres. In order to exclude the possible effects of commercial sizing on the interfacial shear strength and to improve the uniformity of the porous

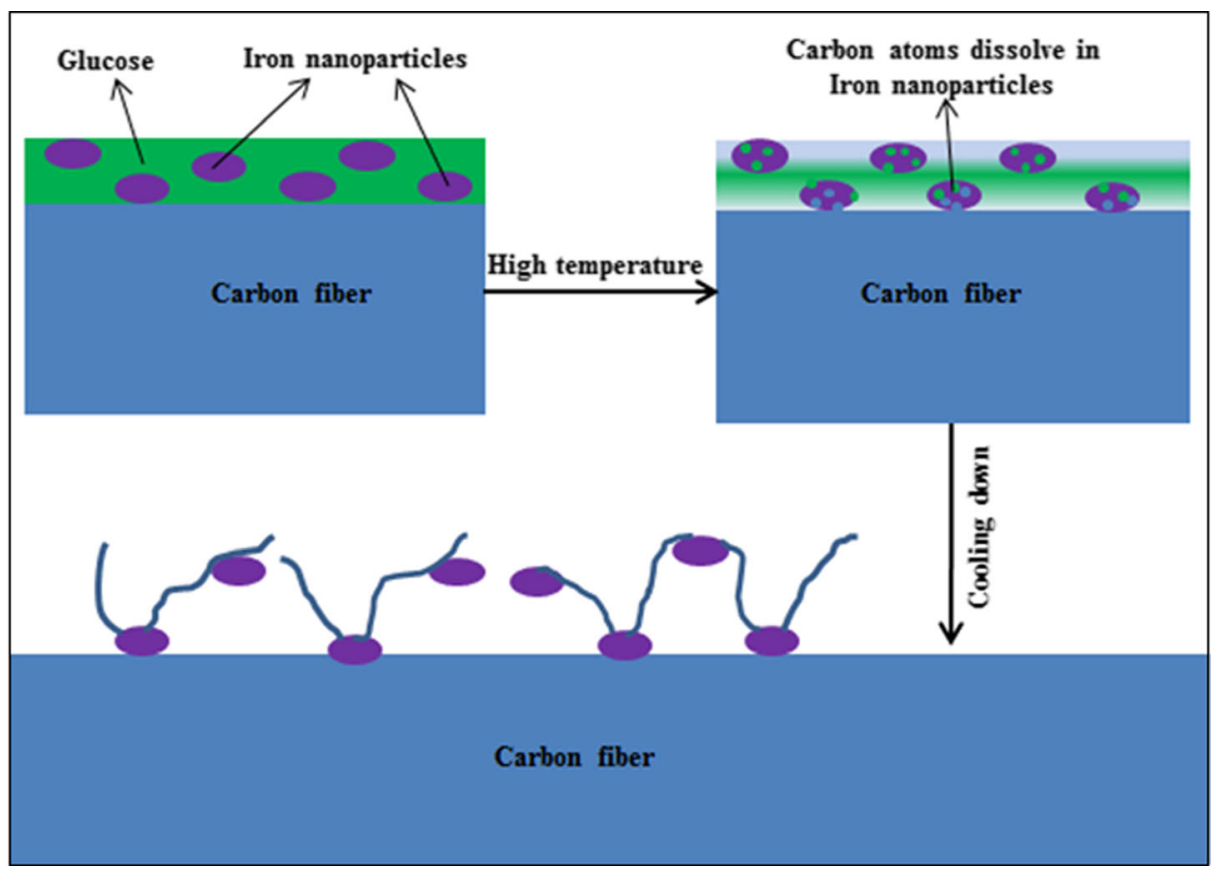

Fig. 1 The methodology of in-situ growth of graphene-related coatings on the surface of carbon fibres 
carbon coating, the size on the fibre surface was removed using two different methods following the practice used by other researchers $[2,11]$. Using the first method, the carbon fibres were immersed into $65 \mathrm{wt} \% \mathrm{HNO}_{3}$ for $1.5 \mathrm{~h}$. Another method allows the carbon fibres to be immersed in acetone solution for $48 \mathrm{~h}$. After the removal of the size from the carbon fibre surface, the carbon fibres were fully immersed into the mixed solution mentioned above before drying the fibres in an oven at $80^{\circ} \mathrm{C}$ for $12 \mathrm{~h}$. Then the samples were then transferred to the tube furnace with the protection of $\mathrm{Ar} / \mathrm{H}_{2}$ gas in a (95:5) ratio atmosphere. The maximum temperature was rasied to $950^{\circ} \mathrm{C}$ at a rate of $5^{\circ} \mathrm{C} / \mathrm{min}$ and maintained for $6 \mathrm{~h}$ according to the findings in previous studies [7, 13-15]. Finally, the sample was cooled down to room temperature. This process is illustrated in Fig. 2.

\section{Characterisation of Results and Discussions}

\subsection{Characterisation of the Modified Method from Using Silicon Substrate}

The weight ratio between the ferrous sulfate heptahydrate $\left(\mathrm{FeSO}_{4} \cdot 7 \mathrm{H}_{2} \mathrm{O}\right)$ and D-glucose monohydrate $\left(\mathrm{C}_{6} \mathrm{H}_{12} \mathrm{O}_{6} \cdot \mathrm{H}_{2} \mathrm{O}\right)$ and the heating temperature was decided through the preliminary experiments using silicon wafer as the substrate. The growth of the graphene is controlled by changing the heating temperature, heating time, and the ratio of carbon source to catalyst. Based on the preliminary experiments on forming grapheme on silicon substrate, the optimal conditions for graphene growth are $950^{\circ} \mathrm{C}$ as the maximum temperature, $6 \mathrm{~h}$ heating time at the maximum temperature, and 10:1 ratio between the carbon sourse and the catalyst precursors. The solution on the silicon substrates was heated in the tube furnace under high temperature and an Argon $/ \mathrm{H}_{2}$ atmosphere. Then the residues of the reacted solution were characterised by using scanning electron microscopy (SEM/Ultra 55) and Raman spectroscopy (Renishaw $1000514 \mathrm{~nm}$ Argon-ion laser). The SEM results demonstrated that a porous carbon structure have been generated from the residues of the solution as shown in Fig. 3a and b. The dotted structure distributed in the porous carbon structure was shown by SEM to be iron and the rest of the material is carbon under the Energy-dispersive X-ray Analysis (EDS) mode

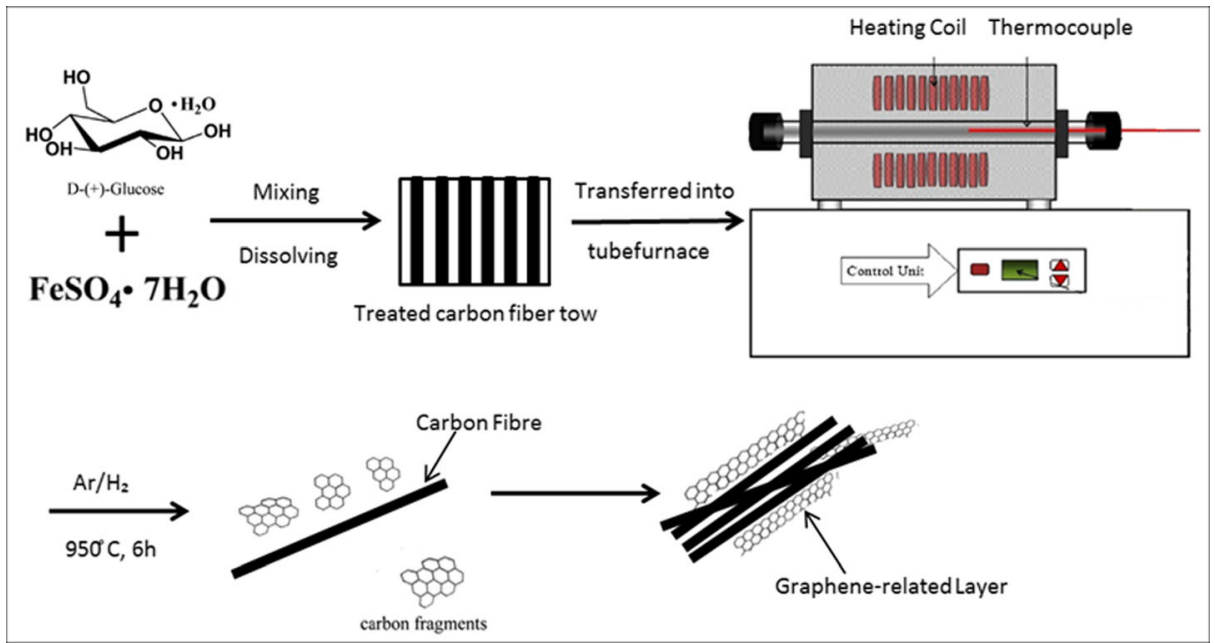

Fig. 2 The experiment of in-situ growth of graphene-related coatings on the surface of carbon fibres 


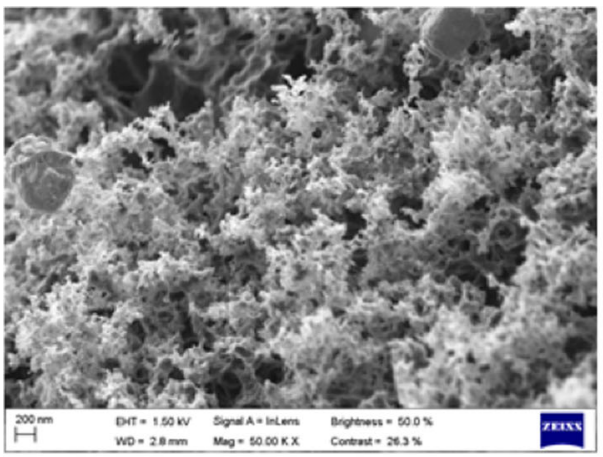

(a)

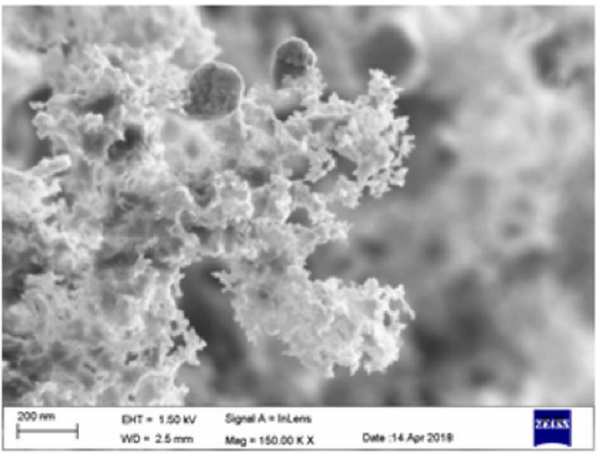

(b)

Fig. 3 a and $\mathbf{b}$ The porous carbon structure generated from the reacted Ferrous Sulfate Heptahydrate and Dglucose monohydrate mixed solutions

shown in Fig. 4a, b and c. There should be graphene-related structures generated in the porous carbon structures according to the achieved Raman spectrum results.

The Raman spectrum Fig. 5 indicated that it consists of two prominent peaks at around $\sim 1330$ and $\sim 1600 \mathrm{~cm}^{-1}$ along with a wide band extending from about $2600-3200 \mathrm{~cm}^{-1}$. The peaks at $\sim 1330$ and $\sim 1600 \mathrm{~cm}^{-1}$ are the $\mathrm{D}$ and $\mathrm{G}$ bands respectively $[17,18]$. The $\mathrm{G}$ band is a characteristic of all graphitic structures. The D band is attributed to the presence of defects, wrinkle formation and the presence of functional groups $[19,20]$. The wide band the high frequency end of the spectrum contains three peaks around $2650 \mathrm{~cm}^{-1}, 2930 \mathrm{~cm}^{-1}$ and 3190 $\mathrm{cm}^{-1}$, respectively. The peak at $\sim 2650$ is known as the $2 \mathrm{D}$ band since it is an overtone of the $\mathrm{D}$ band. While unlike the 2D peak of the perfect monolayer graphene which has high intensity and a lorentzian shape, the 2D peak indicated a few layered graphene depositions, and is complex in shape and evolves with the number of layers [21].

\subsection{The Effect of the Desizing with Different Method}

The changes in surface topography for the carbon fibres after different treatment methods were verified by SEM analysis. The darker areas along the fibre axis can be seen on the surface of commercial fibre as shown in Fig. 6a. After removing the commercial sizing by using acetone and $\mathrm{HNO}_{3}$, the desized carbon fibre with no darker areas can be observed and the longitudinal grooves on the surface of carbon fibres were exposed and no obvious damage was observed as illustrated in Figs. $6 \mathrm{~b}$ and c, apart from the exposed longitudinal grooves on the surface of the

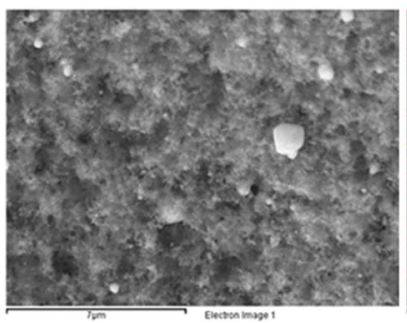

(a)

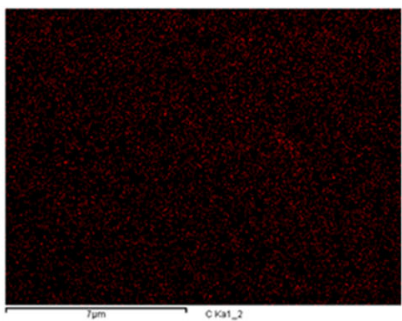

(b)

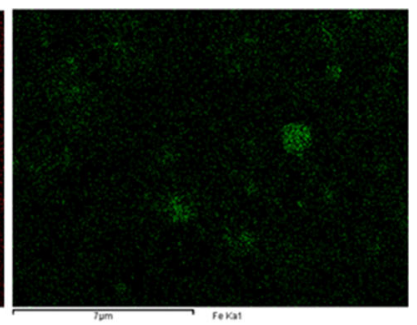

(c)

Fig. 4 a The SEM image of the porous carbon structure b The $\mathrm{C}$ element in the porous carbon structure under the EDS mode of the SEM $\mathbf{c}$ The Fe element distribution in the porous carbon structure under the EDS mode of the SEM 


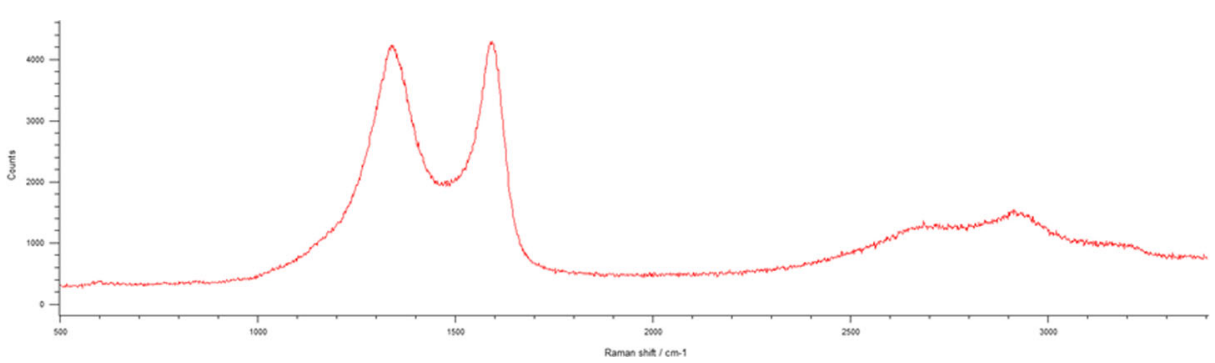

Fig. 5 Characterisation results of the residues of the reacted Ferrous Sulfate Heptahydrate and D-glucose monohydrate mixed solutions analysied by using Raman spectroscopy

carbon fibres. Tensile test was also carried out to verify the damage caused by removing the size from the carbon fibre. 20 tests were carried out for sized and desized carbon fibres. It was found that the tensile strength of the carbon fibres desized using acetone and $\mathrm{HNO}_{3}$ reduced 7 and $5 \%$ respectively compared to the commercial carbon fibres.

\subsection{In-Situ Growth of Graphene on Carbon Fibres}

The raw carbon fibre treated with solution and then heated in the tube-furnace are shown in Fig. $7 \mathrm{a}$ and indicated that there is only small amount of porous carbon structure coating was

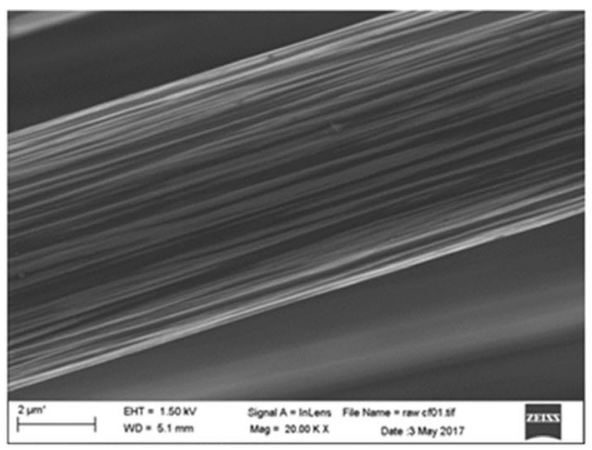

(a)

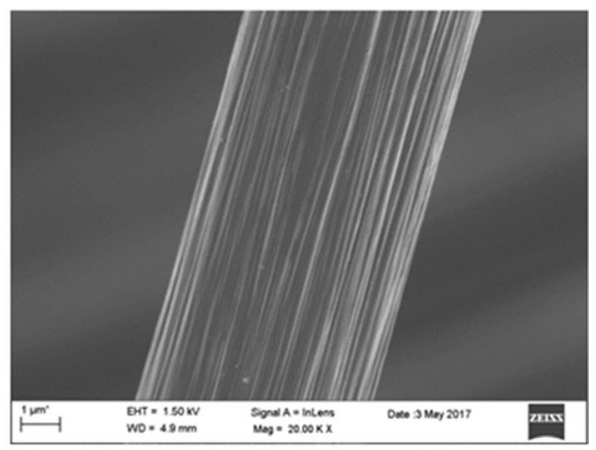

(b)

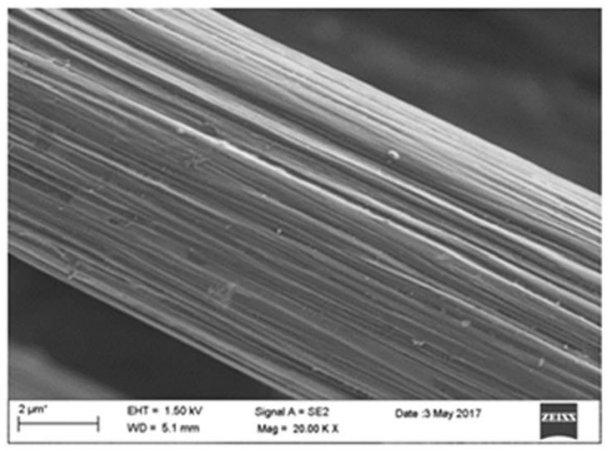

(c)

Fig. 6 a Raw carbon fibres b Desized carbon fibres by using Acetone c Desized carbon fibres by using $\mathrm{HNO}_{3}$ 
grown on the surface of the sized carbon fibres. A more uniform coating was grown on the surface of the desized carbon fibres as shown in Fig. $7 \mathrm{~b}$ and $\mathrm{c}$. This is caused by the sizing on surface of the carbon fibres that lead to the uneven of the solution on the surface of carbon fibres. The longitudinal grooves on the surface of the carbon fibre after treating by $\mathrm{HNO}_{3}$ and Acetone can help to load the solution better compared with the raw carbon fibre [10].

\section{Conclusion}

The preliminary experiment results that characterised by Raman spectroscopy shown that there are three peaks at around $\sim 1330 \mathrm{~cm}^{-1}$ and $\sim 1600 \mathrm{~cm}^{-1}$ along with a wide band extending from about $2600-3200 \mathrm{~cm}^{-1}$, which indicated there should be graphene layers in the porous carbon structure. However, different characterisation methods such as TEM and XPS also should be used to help to produce incontrovertible results.

The SEM image demonstrated that the raw carbon fibres treated with mixed solution samples have the worst coating compared with the desized samples, which indicated that the commercial sizing does affect the uniformity of the graphene-related coatings. Thus, the commercial sizing needs to be removed to reduce the effect on the growth of the graphenerelated layer on the surface of the carbon fibres. In addition, the tensile property of the carbon

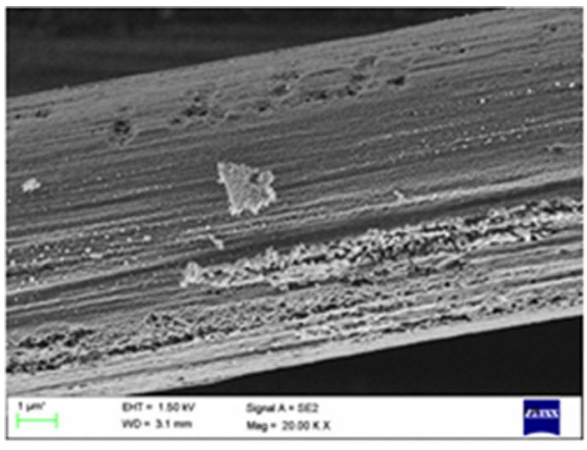

(a)

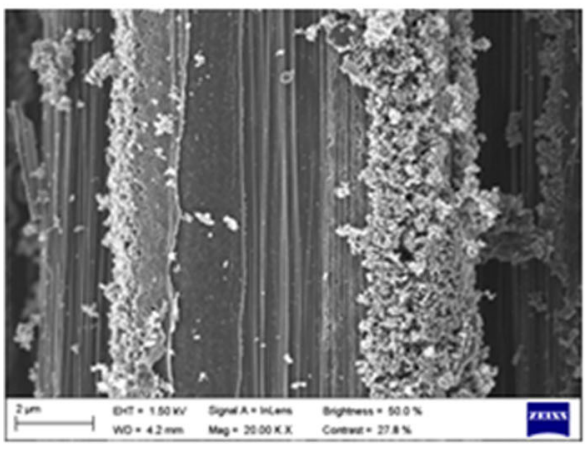

(c)

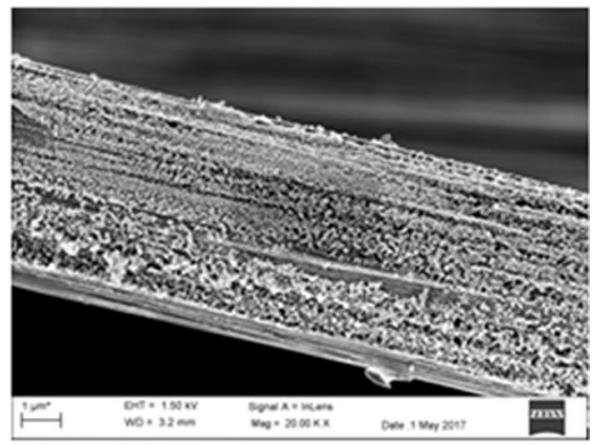

(b)

Fig. 7 a Raw carbon fibre treated with Ferrous/glucose solution b Desized carbon fibre (with Acetone) and treated with Ferrous/glucose solution c Desized carbon fibre (with $\mathrm{HNO}_{3}$ ) and treated with Ferrous/glucose solution 
fibre have not been affected too much after size removal from the carbon fibre, which have reduced 7 and $5 \%$ respectively by using acetone and $\mathrm{HNO}_{3}$.

The graphene-related coatings have been in-situ grown on the surface of the carbon fibres but more characterisation methods need to be applied to characterise the bonding between the generated coatings and the carbon fibre. On the other hand, the composite will need to be manufactured to identify the property of the modified carbon fibre reinforced composites.

Open Access This article is distributed under the terms of the Creative Commons Attribution 4.0 International License (http://creativecommons.org/licenses/by/4.0/), which permits unrestricted use, distribution, and reproduction in any medium, provided you give appropriate credit to the original author(s) and the source, provide a link to the Creative Commons license, and indicate if changes were made.

\section{References}

1. Yao, H., et al.: Optimization of interfacial microstructure and mechanical properties of carbon fiber/epoxy composites via carbon nanotube sizing. Appl. Surf. Sci. 347, 583-590 (2015)

2. Zhang, X., et al.: Interfacial microstructure and properties of carbon fiber composites modified with graphene oxide. ACS Appl. Mater. Interfaces. 4(3), 1543-1552 (2012)

3. Sager, R., et al.: Effect of carbon nanotubes on the interfacial shear strength of T650 carbon fiber in an epoxy matrix. Compos. Sci. Technol. 69(7), 898-904 (2009)

4. Xu, L.W., Huang, Y., and Liu, L. The Effect of Physical Properties on the Interfacial Adhesion of Fiber Reinforced Resin Composites. In Advanced Materials Research. 2011. Trans Tech Publ

5. Shazed, M., et al.: Effect of fibre coating and geometry on the tensile properties of hybrid carbon nanotube coated carbon fibre reinforced composite. Mater. Des. 54, 660-669 (2014)

6. Li, F., et al.: Enhanced mechanical properties of short carbon fiber reinforced polyethersulfone composites by graphene oxide coating. Polymer. 59, 155-165 (2015)

7. Zhang, L., et al.: In situ growth of three-dimensional graphene coatings on arbitrary-shaped micro/nano materials and its mechanism studies. Carbon. 92, 84-95 (2015)

8. Pang, J., et al.: CVD growth of 1D and 2D sp2 carbon nanomaterials. J. Mater. Sci. 51(2), 640-667 (2016)

9. Marcano, D.C., et al., Improved Synthesis of Graphene Oxide. 2010

10. Zhao, J., et al.: Growth of carbon nanotubes on the surface of carbon fibers. Carbon. 46(2), 380-383 (2008)

11. Li, Y., et al.: A novel multiscale reinforcement by in-situ growing carbon nanotubes on graphene oxide grafted carbon fibers and its reinforced carbon/carbon composites with improved tensile properties. Journal of Materials Science \& Technology. 32(5), 419-424 (2016)

12. Rodríguez-Manzo, J.A., Pham-Huu, C., Banhart, F.: Graphene growth by a metal-catalyzed solid-state transformation of amorphous carbon. ACS Nano. 5(2), 1529-1534 (2011)

13. Li, J., et al.: In-situ growth of graphene decorations for high-performance LiFePO 4 cathode through solidstate reaction. J. Power Sources. 249, 311-319 (2014)

14. Sevilla, M., Fuertes, A.B.: Catalytic graphitization of templated mesoporous carbons. Carbon. 44(3), 468474 (2006)

15. Wu, G., et al.: High-performance electrocatalysts for oxygen reduction derived from polyaniline, iron, and cobalt. science. 332(6028), 443-447 (2011)

16. Qian, H., et al.: Hierarchical composites reinforced with carbon nanotube grafted fibers: the potential assessed at the single fiber level. Chem. Mater. 20(5), 1862-1869 (2008)

17. Bajpai, R., et al.: Graphene supported nickel nanoparticle as a viable replacement for platinum in dye sensitized solar cells. Nanoscale. 4(3), 926-930 (2012)

18. Eckmann, A., et al.: Probing the nature of defects in graphene by Raman spectroscopy. Nano Lett. 12(8), 3925-3930 (2012)

19. Ferrari, A.C., et al.: Raman spectrum of graphene and graphene layers. Phys. Rev. Lett. 97(18), 187401 (2006)

20. Ferrari, A.C.: Raman spectroscopy of graphene and graphite: disorder, electron-phonon coupling, doping and nonadiabatic effects. Solid State Commun. 143(1), 47-57 (2007)

21. Gupta, A., et al.: Raman scattering from high-frequency phonons in supported n-graphene layer films. Nano Lett. 6(12), 2667-2673 (2006) 